AperTO - Archivio Istituzionale Open Access dell'Università di Torino

A relaxometric method for the assessment of intestinal permeability based on the oral administration of gadolinium-based MRI contrast agents

This is a pre print version of the following article:

Original Citation:

Availability:

This version is available http://hdl.handle.net/2318/1563529

since 2017-05-15T15:41:14Z

Terms of use:

Open Access

Anyone can freely access the full text of works made available as "Open Access". Works made available under a Creative Commons license can be used according to the terms and conditions of said license. Use of all other works requires consent of the right holder (author or publisher) if not exempted from copyright protection by the applicable law. 


\section{A relaxometric method for assessing Intestinal Permeability based on the oral administration of Gd-based MRI contrast agents}

Measuring intestinal permeability with MRI contrast agents

Eliana Gianolio ${ }^{\mathrm{a}}$, Cinzia Boffa ${ }^{\mathrm{a}}$, Valeria Orecchia ${ }^{\mathrm{a}}$, Paola Bardini ${ }^{\mathrm{a}}$, Valeria

Catanzaro $^{\mathrm{a}}$,Valeria Poli ${ }^{\mathrm{a}}$, Silvio Aime $\mathrm{a}^{\mathrm{a}^{*}}$

a Department of Molecular Biotechnology and Health Sciences, University of Torino, Via Nizza

52, 10126, Torino, Italy

* Corresponding author: Silvio Aime, e-mail: silvio.aime@unito.it, tel: +390116706451, fax:

$+390116706487$

Keywords: Gd chelate based Contrast Agents, Gastrointestinal, Relaxometry, Intestinal Permeability, Colitis

\section{Abbreviations:}

CAs : Contrast Agents

IBD: Inflammatory Bowel Disease

IBS: Irritable Bowel Syndrome

IPT: Intestinal Permeability Test

DSS: Dextran Sulfate Sodium

H\&E: Hematoxylin and Eosin

word count: 4656 


\section{Abstract}

Herein a new relaxometric method to assess intestinal permeability based on the oral administration of clinically approved Gd-based MRI contrast agents (CAs) is proposed. The fast, easily performed and cheap measurement of the longitudinal water proton relaxation rate $\left(R_{1}\right)$ in urine reports about the amount of the paramagnetic probe that has escaped the gastrointestinal tract. The proposed method appears to be a compelling alternative to the available methods to assess the intestinal permeability. The method has been tested on the murine model of Dextran Sulphate Sodium (DSS)-induced colitis in comparison with healthy mice. Three CAs were tested, namely ProHance ${ }^{\circledR}$, MultiHance ${ }^{\circledR}$ and Magnevist ${ }^{\circledR}$. Urine was collected for 24 hours after the oral ingestion of the Gd-containg CA at day 3-4 (severe damage stage) and day 8-9 (recovering stage) after the treatment with DSS. The amount of Gd content in urine measured by ${ }^{1} \mathrm{H}$ relaxometry was confirmed by ICP-MS. The extent of urinary excretion was given as percentage of excreted Gd over the total ingested dose. The method has been validated by comparing the obtained results with the established methodology based on the Lactulose/Mannitol and Sucralose tests. For ProHance ${ }^{\circledR}$ and Magnevist ${ }^{\circledR}$ the excreted amounts in the severe stage of the damage are 2.5-3 times higher than in control mice. At the recovering stage no significant differences have been observed with respect to healthy mice. Overall, a good correlation with the Lactulose/Mannitol and Sucralose results has been obtained. In the case of MultiHance ${ }^{\circledR}$, the percentage of excreted Gdcomplex was not significantly different from that of control mice neither in the severe and recovering stages. The difference with ProHance ${ }^{\circledR}$ and Magnevist ${ }^{\circledR}$ has been explained on the basis of the (known) partial biliary excretion of MultiHance ${ }^{\circledR}$ in mice. 


\section{Introduction}

The ability of intestinal epithelium to function as a barrier between the external environment and the closely regulated internal domain is essential for human health. The disruption of this barrier system results in a "leaky" intestine. Increased intestinal permeability is associated with several diseases including Inflammatory Bowel Diseases (IBD) (1), Irritable Bowel Syndrome (IBS) (2,3), Celiac Disease (4), Crohn’s Disease (5) and food allergy.

Along the years, several methods have been tested for assessing changes in the intestinal microvasculature associated to the presence of inflammatory processes, such as the use of fiberoptic confocal imaging (6) , or the rotational side-view confocal endomicroscopy (7) or DCE-MRI colonography (8). The intestinal inflammation is invariantly accompanied by lesions in the intestinal epithelium which lead to an increase in the intestinal permeability. Often, Intestinal Permeability Tests (IPTs), based on the oral ingestion of molecules that cannot be metabolized, are used. By this approach, the extent of urine excretion of these molecules is taken as reporter to detect intestinal dysfunction $(9,10)$.

IPTs are based on the differential intestinal absorption of two inert molecular probes (of different size) that are administered orally. Urine is typically collected 6-12 h after the oral administration of the probes in order to assess their eventual release through the leaky intestine and their subsequent renal excretion via the blood circulation. Small probes (the most used are Mannitol (M) or Rhamnose ( R) (MW 182 Da for both)) are thought to cross the intestinal barrier freely. A second, larger probe, usually a disaccharide such as Lactulose (L) (MW 342 Da), permeates only when the barrier 
integrity is lost but it is affected in the same way as the small probe by the pre- and post-mucosal confounders. The ratio between the amounts of disaccharide and monosaccharide $(\mathrm{L} / \mathrm{M})$ in urine is thus considered as a reporter of the loss of intestinal barrier function. For the study of colonic permeability, urine has to be collected for a time longer than 6 hours and the used probes have to be well resistant to the attack of colonic bacteria. Among the sugar-based probes, Sucralose (S) (MW 397.6 Da), which is a chlorinated derivative of sucrose, appears to pass through all the digestive tract unaltered and so it has been proposed a sensitive reporter of damages along all the intestinal tract $(11,12)$. The amount of the sugar-based probes present in the urine has been measured by several methods, namely, enzyme assays, high performance liquid chromatography (HPLC), liquid chromatography in combination with mass spectrometry and Pulsed Amperometric Detection (13).

Other intestinal permeability tests include the absorption/excretion of ${ }^{51}$ Cr-EDTA $(14,15),{ }^{51} \mathrm{Cr}-E D T A /{ }^{14} \mathrm{C}-$ Mannitol excretion ratio (16), polyethylene glycol (17) and Dxylose (18), X-ray contrast media $(19,20)$, but the gold standard, for small bowel diseases, remains the $\mathrm{L} / \mathrm{M}$ test.

Herein, a new method based on the oral administration (and urine detection) of clinically approved Gd-based MRI contrast agents is proposed. The Gd(III)-complexes here investigated (Gd-HPDO3A, Gd-DTPA and Gd-BOPTA) are actually extensively used in the clinical practice as MRI contrast agents because they markedly enhance the water proton relaxation rate of tissue water protons (21). In recent years, contrast enhanced MRI has also emerged as a useful modality for enterography and colonography, both in clinical and preclinical research, to monitor inflammation in IBD $(22,23)$ and in colon cancer $(24,25)$. Moreover, the intravenous injection of a 
macromolecular contrast agent, based on the Albumin-GdDTPA conjugate, has been used to report on changes in vascular permeability in murine colitis models (8).

The quantitative detection of the Gd-based probes in urine relies on a method that is very easy to implement because the paramagnetism of the $\mathrm{Gd}^{3+}$ ions causes a decrease of the water proton relaxation time $\left(\mathrm{T}_{1}\right)$, that is proportional to the concentration of the agent (26). The measure of the longitudinal relaxation rate $\left(\mathrm{R}_{1 \mathrm{obs}}=1 / \mathrm{T}_{1 \mathrm{obs}}\right)$ can be carried out on any NMR spectrometer with a semiautomatic procedure which requires from 1 to 5 minutes depending on the concentration of the paramagnetic probe in urine. As no sample preparation nor external calibration is required, the $\mathrm{T}_{1}$-based method results in a much faster procedure with respect to the "gold standard" HPLC or HPLC/MS analysis. The Gd-complexes are relatively large molecules (MW 500-1000 Da), highly hydrophilic and are not degraded by the colon bacteria, so they appear excellent candidates to report on membrane damages along all the intestinal tract.

The method has been tested on a murine model of colitis induced through the administration of Dextran Sulfate Sodium (DSS) in the drinking water to BALB/c mice (27). In this model, in which small intestine's permeability is not altered, an increase in the urinary concentration of the Gd-based probes is considered indicative of enhanced colonic permeability.

\section{Experimental}

\section{Materials}


Three Gd-based contrast agents (CAs) were tested, namely Gd-HPDO3A (ProHance ${ }^{\circledR}$ Gadoteridol, Bracco Imaging), Gd-BOPTA (MultiHance ${ }^{\circledR}$-Gadobenate dimeglumine, Bracco Imaging) and Gd-DTPA (Magnevist ${ }^{\circledR}$-Gadopentetate dimeglumine, Bayer). Mannitol, Lactulose and Sucralose have been purchased from Sigma-Aldrich.

\section{Colitis animal model}

BALB/c mice ( $\mathrm{n}=50$ in total) were bred in the animal house facility of the Molecular Biotechnology Center (University of Turin, Turin, Italy) under standard conditions of temperature and light, and given water and food ad libitum. Procedures were carried out in conformity with national and international laws and policies as approved by the University Ethical Committee.

Colitis was induced in six-week-old male mice (20-25 g body weight) by addition of 3\% DSS (w/v, final concentration, MP Biomedicals, MW 35,000-50,000 Da) to their drinking water for 5 days, followed by 4 days with normal drinking water, as described previously (27). Mice were daily assessed for colitis symptoms. The clinical course of the disease was represented by a colitis clinical score (28), that was determined as the sum of the scores assigned for the following items: i) body weight loss $(0$, none; $1,1-$ 5\%; 2, 5-10\%; 3, 10-20\%; 4, more than 20\%), ii) stool consistency (0, well formed pellets; 2, pasty and semiformed stools; 4, liquid stools), and iii) the presence or absence of fecal blood (0, negative; 2, light bleeding; 4, marked bleeding). Accordingly, the score can range from 0 (healthy) to 12 (maximal colitis activity). At day 9 from the beginning of DSS treatment, animals were sacrificed, colons removed and their length measured from the anus to the beginning of caecum, as an indirect marker of inflammation. Colons were then prepared as Swiss rolls (28), fixed in $4 \%$ buffered 
formaldehyde and subsequently embedded in paraffin for histopathological analysis of H\&E stained-sections.

Study design

The study design is schematically illustrated in scheme 1.

A pilot experiment was set up to assess whether the proposed methodology yields results consistent with the established sugar based method.

Mice (n=10 per group), including colitis and controls, were fed overnight with iron/manganese-free diet and administered with an oral dose (200 $\mu \mathrm{l})$ consisting of ProHance $^{\circledR}$ (4.56 $\mu$ moles) and a mix of sugars (Lactulose 0.0584 mmoles, Mannitol 0.11 mmoles and Sucralose 0.0503 mmoles) at day 3 after the beginning of DSS treatment. Urine was then collected, by using proper metabolic cages which allow for a continuous urine collection (avoiding interferences with stool), for $24 \mathrm{~h}$ in two slots, i.e. over the first $0-6 \mathrm{~h}$ and the successive 6-24h, respectively. On the assumption that renal excretion is fast (ca. $30 \mathrm{~min}$ ), the chosen time slots allow to evaluate the permeability within small (0-6h) and large (6-24h) intestine, respectively (29-31). Total volumes of collected urines were recorded and $1 \mathrm{ml}$ from each slot was stored at $-20^{\circ} \mathrm{C}$ until used for ICP-MS (for the determination of Gd content) and HPLC-MS (for the determination of sugars content) analyses.

Next, in the second study, ProHance ${ }^{\circledR}$ has been compared with two other established MRI contrast agents (MultiHance ${ }^{\circledR}$ and Magnevist ${ }^{\circledR}$ ) by applying the relaxometric methodology.

At days 3 and 8 after starting the DSS treatment, as above, all mice ( $\mathrm{n}=5$ per group), including colitis and controls, were orally administered with a bolus $(120 \mu \mathrm{l})$ of water solutions of ProHance ${ }^{\circledR}$, MultiHance ${ }^{\circledR}$ or Magnevist ${ }^{\circledR}$ (4.56 $\mu$ moles), respectively. The 
urine collection was carried out for $0-6 \mathrm{~h}$ and $6-24 \mathrm{~h}$, as described above. Individual volumes of collected urines over each time interval were recorded and the longitudinal relaxation rates were measured. ICP-MS analysis for the determination of the total Gd urinary excretion was carried out only on the overall $24 \mathrm{~h}$ collection for each mouse.

Relaxometric analysis of urines and Gd content determination

Longitudinal relaxation rates $\left(\mathrm{R}_{1}\right)$ of the collected urine samples were measured at 21.5MHz and $25^{\circ} \mathrm{C}$ on a Stelar Spinmaster relaxometer (Stelar, Mede (Pavia), Italy) using the standard inversion-recovery technique. The temperature was controlled with a Stelar VTC-91 air-flow heater equipped with a copper constantan thermocouple (uncertainty $0.1^{\circ} \mathrm{C}$ ). To correct for the different collected urine volumes, $\mathrm{R}_{1}$ data were reported as R1obs $\times$ Volume of the collected urine specimen. Gd content in urine samples was measured by ICP-MS analysis (Element-2; ThermoFinnigan, Rodano (MI), Italy) and the relative amount of excreted Gd-complex was given as percentage of excreted Gd over the total ingestion dose. The preparation of the samples for ICP-MS analysis has been carried out as follows: i) $100 \mu$ l of each urine sample was mineralized with $1 \mathrm{ml}$ of concentrated $\mathrm{HNO}_{3}$ (70\%) under microwave heating at $160^{\circ} \mathrm{C}$ for 40 minutes (Milestone MicroSYNTH Microwave lab station equipped with an optical fiber temperature control and HPR-1000/6M six position highpressure reactor, Bergamo, Italy); ii) after mineralization, the volume of each sample was brought to $2 \mathrm{ml}$ with ultrapure water and the sample was analyzed by ICP-MS. The calibration curve was obtained using four gadolinium absorption standard solutions (Sigma-Aldrich) in the range $0.005-0.1 \mu \mathrm{g} / \mathrm{ml}$. 
Separation and quantification of Mannitol, Lactulose and Sucralose was obtained by HPLC-ESI-MS analysis (Waters; 515 HPLC pump-3100 mass detector) in positive acquisition mode (Capillary voltage $4.00 \mathrm{KV}$, Cone voltage $40 \mathrm{~V}$, Source Temperature $110^{\circ} \mathrm{C}$, Desolvation temperature $250^{\circ} \mathrm{C}$ ). The quantification was achieved through proper calibration curves obtained by adding to fresh urine samples aliquots of an appropriate internal standard (Raffinose), to a final concentration of $500 \mu \mathrm{M}$, and aliquots of the sugars to be analyzed (Mannitol, Lactulose and Sucralose), to a final concentration of $500 \mu \mathrm{M}$, (in triplicate). From these calibration measurements it was possible to calculate the conversion factor $(\mathrm{K})$ between the areas under the Lactulose, Mannitol and Sucralose peaks and those ones relative to Raffinose. Samples were prepared as follows: i) addition of $60 \mu \mathrm{l}$ of Raffinose $4 \mathrm{mM}$, as internal standard, to 500 $\mu \mathrm{l}$ of urine, ii) vortex mixing and centrifugation for $10 \mathrm{~min}$ at $12000 \mathrm{rpm}$ and iii) filtration of the supernatant through $0.2 \mu \mathrm{m}$ syringe filters. The chromatographic separation (injection volume: $2 \mu \mathrm{l}$ ) of sugars was achieved through a $\mathrm{RP} \mathrm{C}_{18}$ column (Phenomenex, Luna HILIC $3 \mu \mathrm{m}, 150 * 200 \mathrm{~mm}$ ) by isocratic elution with mobile phase A (Lithium Acetate $5 \mathrm{mM}, \mathrm{pH}=7$ ) set at $15 \%$ and mobile phase $\mathrm{B}$ (acetonitrile) set at 85\%. Flow rate was $0.2 \mathrm{ml} / \mathrm{min}$ for a total HPLC analysis time of $25 \mathrm{~min}$ (for each sample).

Analyte sugars peaks were identified (table 1) and quantified respect to the internal standard area.

Raw HPLC/MS data were converted to Sucralose excretion (\%) and Lactulose/Mannitol $(\mathrm{L} / \mathrm{M})$ ratio according to the following equations:

$\%$ excreted sucralose $=\frac{[\text { sucralose from } H P L C-M S] \times \text { urine volume }}{\text { administered moles }} \times 100$ 


$$
\frac{L}{M}=\frac{\% \text { excreted lactulose }}{\% \text { excreted mannitol }}
$$

The $\mathrm{L} / \mathrm{M}$ ratio values were measured in samples relative to the $0-6 \mathrm{~h}$ urine collections while the \% excreted Sucralose values were measured in samples relative to the $6-24 \mathrm{~h}$ collections.

\section{Statistical analysis}

Data are represented as mean \pm SD. Comparison between groups was carried out by using an unpaired data Student's t-test. Differences between groups were considered significant at $95 \%\left(^{*}\right)$ with $\mathrm{P}<0.05$, at $99 \%(* *)$ with $\mathrm{P}<0.01$ and at $99.9 \%(* * *)$ with $\mathrm{P}<0.001$.

\section{Results and Discussion}

\section{Colitis Model and damage assessment}

Mice were subjected to DSS-induced colitis as described in the Experimental section. Control mice received regular drinking water. The extent of DSS-induced colitis was judged by various parameters, such as clinical score, colon length and histological features. All mice exposed to the DSS treatment displayed a consistently high clinical score, assessed by weight loss, stool consistency and bleeding as described in the Experimental section (Table 2). In addition, all DSS-treated mice showed a significant shortening of the colon length with respect to their healthy controls; this item is considered an important inflammation index. The lowest clinical score (score $=1$ ) 
assigned to control mice is due to a slight weight loss as a consequence of the administered iron/manganese-free diet. Histological analysis of the colon sections from DSS-treated mice showed typical inflammatory alterations in the colon architecture, such as ulcerations, surface epithelial loss, crypt destruction and abundant inflammatory infiltrate (Figure 2).

Validation of the use of the Gd-based complexes as intestinal permeability probes vs the established sugars-based method

The herein proposed method consists of the oral administration of paramagnetic Gd(III)-complexes and the measure of ${ }^{1} \mathrm{H}$-relaxation times of urine samples. The used Gd(III)-complexes are clinically approved MRI contrast agents that markedly enhance the water proton relaxation rate of their aqueous solutions. When administered orally, they are expected to be excreted unaltered in the feces. In the presence of enhanced intestinal permeability, part of the administered dose is expected to pass into blood and to be excreted in urine.

The proposed method has been validated against the well-established intestinal permeability test based on the use of sugars' mixture. DSS-treated mice and healthy controls ( $\mathrm{n}=10$ for each group) were orally administered with a solution consisting of ProHance $^{\circledR}(4.56 \mu \mathrm{mol})$ and a mix of sugars (Lactulose $0.0584 \mathrm{mmol}$, Mannitol 0.11 mmol and Sucralose $0.0503 \mathrm{mmol}$ ) at day 3 after the beginning of DSS treatment followed by a 24h urine collection as described in the Experimental section, divided into two intervals, e.g. 0 -6h, for assessing the escape from the small bowel tract, and 624h, to investigate the colon permeability, respectively (29-31). The collected urine 
samples underwent two analysis: i) ICP/MS measurements in order to determine the percentage of excreted Gd-complex with respect to the total administered dose; ii) HPLC/MS for the quantification of the Lactulose/Mannitol (L/M) ratio in the 0-6h collections and the percentage of excreted Sucralose in the 6-24h samples, respectively. Small intestine damages have been traditionally evaluated through the measure of $\mathrm{L} / \mathrm{M}$ ratio, while Sucralose, a chlorinated sucrose molecule which is considered to pass through all the digestive tract unaltered, has been used to measure permeability alterations in the colonic tract (11). Inspection into the data reported in Figure 3 shows that the results obtained from the two sets of measurements are in very good agreement (correlation significant at $99 \%$ in Fig 3D), both underlying a highly significant difference between healthy and colitis mice in the 6-24h urine collections. Moreover, in the 0 -6h urine samples, which are investigated to report on alterations in the small intestine, no significant difference has been observed between healthy and treated mice both with the sugars mix and with the Gd-based method. The damage inferred through the administration of DSS is in fact at the level of the colon tract (28).

\section{Set-up of the ${ }^{1}$ H-relaxometric method}

Once demonstrated that the use of ProHance ${ }^{\circledR}$ provides a reliable assessment of colon permeability alterations in colitis mice, the simple and fast relaxometric method based on the measure of the relaxation rates $\left(1 / T_{1}\right)$ of the collected urines has been set-up. The observed relaxation rate $\left(\mathrm{R}_{1 \text { obs }}\right)$ of a water solution containing a paramagnetic Gdcomplex, measured at a given proton Larmor frequency and temperature, is in fact dependent from the concentration of the probe with a linear correlation: 


$$
R_{1 \circ b s}=T_{1 p} \times[G d L]+R_{1 d}
$$

Where $r_{1 p}$ is the millimolar relaxivity of the paramagnetic probe, [GdL] is its concentration ( $\mathrm{mM}$ ) and $\mathrm{R}_{1 \mathrm{~d}}$ is the diamagnetic urine contribution measured in the absence of the paramagnetic species in control (not DSS treated) mice $\left(0.348 \pm 0.009 \mathrm{~s}^{-1}\right.$ at $21.5 \mathrm{MHz}$ and $25^{\circ} \mathrm{C}$ ).

As the urinary composition of control and DSS induced colitis mice could be different, $\mathrm{R}_{1 \mathrm{~d}}$ of urines collected from mice at day 3-4 of DSS treatment (acute phase) were also measured. The mean value $(n=24)$ resulted to be $0.340 \pm 0.005 \mathrm{~s}^{-1}$ (at $21.5 \mathrm{MHz}$ and $\left.25^{\circ} \mathrm{C}\right)$, thus not significantly different $(\mathrm{P}=0.4265)$ from that of healthy mice urines (Supp. Info - Fig. S1).

The linear dependence of the observed relaxation rates (measured at $21.5 \mathrm{MHz}$ and $25^{\circ} \mathrm{C}$ ) from ProHance ${ }^{\circledR}$ concentration in mouse urine was checked in the concentration range $0.1-1 \mathrm{mM}$ (Supp. Info- Fig. S2). A relaxivity ( $\left.\mathrm{r}_{1 \mathrm{p}}\right)$ value of $5.06 \mathrm{mM}^{-1} \mathrm{~s}^{-1}$ was found, which is slightly higher than the value measured in water (32). This finding can be accounted for the small increase in the viscosity but it rules out the occurrence of any significative interaction of the paramagnetic probe with urine components which, at the applied magnetic field, would markedly increase its relaxivity with respect to neat water solutions.

It was deemed interesting to compare ProHance ${ }^{\circledR}$ with two other Gd-based MRI CAs used in the clinical practice, namely, Magnevist ${ }^{\circledR}$ ([Gd-DTPA $]^{2-}$ Meg $\left._{2}\right]$ ) and MultiHance $^{\circledR}$ ([Gd-BOPTA $]^{2-}$ Meg$\left._{2}\right]$ ) (Figure 1). 
A single dose of each Gd-complex $(4.56 \mu \mathrm{mol})$ was administered orally to mice, treated and not-treated with DSS ( $\mathrm{n}=5$ per each group), at day 3 (severe stage of the damage) and day 8 (repairing stage of the damage) from the start of the DSS treatment. Longitudinal proton relaxation rates ( $\left.\mathrm{R}_{1 \mathrm{obs}}\right)$ of the collected urine samples, splitted in the two slots, from 0 to $6 \mathrm{~h}$ and from 6 to $24 \mathrm{~h}$ collection times, respectively, were measured at $21.5 \mathrm{MHz}$ and $25^{\circ} \mathrm{C}$. ICP-MS determination of the Gd-content in the collected urine samples has been carried out as well.

Figure 4 reports the mean excreted percentage of the total ingestion dose (24h urine collection) for both healthy controls and DSS-treated mice measured at day 3-4 and at day 8-9. At the severe stage of the damage (day 3-4), the excreted dose is 2.5 and 3.1 times higher than in control mice for ProHance ${ }^{\circledR}$ and Magnevist ${ }^{\circledR}$, respectively. On the contrary, in the case of MultiHance ${ }^{\circledR}$, the percentage of excreted agent in DSS-treated mice is not significantly different from that found in the controls. An explanation for this result can be found in the structural features of the investigated Gd-complexes (Figure 1). While Prohance ${ }^{\circledR}$ and Magnevist ${ }^{\circledR}$ are highly hydrophilic molecules with a rapid renal excretion, MultiHance ${ }^{\circledR}$ is functionalized with an hydrophobic benzyl-oxymethyl substituent that promotes its interaction with serum-albumin and consequently drives its marked hepatic transit $(33,34)$. Pavone et al. (35) showed that MultiHance ${ }^{\circledR}$ undergoes biliary (39\%) as well as renal (55\%) excretion. Thus, also in the presence of intestinal leakage, MultiHance ${ }^{\circledR}$ is only partially recovered in urines, as the renal excretion represents only 55\% of the total excreted amount. 
At day 8-9, when the damage was in the "repair" stage, the observed increase of Gdcomplexes in the urine does not appear to be significant with respect to that observed in healthy mice for all tested MRI contrast agents.

As a general remark, it is interesting to note that the three CAs have a very similar renal excretion in healthy mice.

Figures 4B and $\mathrm{C}$ show the clinical score and the colon length of untreated and DSStreated mice. Importantly, none of the Gd-based contrast agents affected colitis parameters. Indeed the colitis score, the shortening of the colon (Figures $4 \mathrm{~B}$ and $\mathrm{C}$ ) and the colon morphology (data not shown) were comparable between DSS-treated mice with or without CA administration.

Figure 5 reports the observed relaxation rates ( $\mathrm{R}_{1 \mathrm{obs}}$ ) data for the $0-6 \mathrm{~h}$ and 6 -24h urine collections for the three CAs. To account for the differences in urine volumes, the observed relaxation rates have been multiplied for the total urine volume. In accordance with the excretion values reported in Figure 4, the relaxation enhancement of urines of mice in the severe stage of colitis is 2.6 and 2.7 fold that of control mice for ProHance ${ }^{\circledR}$ and Magnevist ${ }^{\circledR}$, while the difference decreases significantly in the repairing stage. The results obtained with MultiHance ${ }^{\circledR}$ confirm those ones reported in Fig. 4, as the values obtained for colitis mice were not significantly different from those of control mice.

In vivo MRI experiments were carried out on control and DSS treated mice, at day 4 and 8 after the start of DSS treatment, to assess the kidney and liver distribution of the paramagnetic ProHance ${ }^{\circledR}$ orally administered at $0.015 \mathrm{mmol} / \mathrm{Kg}$ dose (see Supp. Info. Fig. S3). 
The increased urinary excretion of ProHance ${ }^{\circledR}$ in DSS treated mice in the acute phase of the damage (day 4) is accompanied by an increased MR-signal enhancement in kidneys but not in liver (Supplementary Material Fig.S3). 24 hours after the ingestion of the probe, a significantly higher ( $\mathrm{P}=0.04$ with respect to control mice) MR-signal enhancement in kidneys was found in the acute phase of DSS damage but not in the recovery stage. As expected, this neutral and hydrophilic contrast agent has a rapid renal elimination and therefore the portion of the orally administered dose that escapes the leaky intestinal barrier enters the blood circulation from which it is eliminated through the kidneys.

\section{Concluding remarks}

The amounts of ProHance ${ }^{\circledR}$ and Magnevist ${ }^{\circledR}$ orally administered and recovered in the urine of mice with DSS-induced colitis are significantly enhanced and parallel the behavior of the currently used sugar-based intestinal permeability probes. While the actual mechanism(s) for the increased urinary excretion of an orally administered probe in colitis mice remains undetermined and may involve multiple factors, it appears associated to an increased escape from the intestinal barrier, so ProHance ${ }^{\circledR}$ and Magnevist ${ }^{\circledR}$ can be considered good probes to assess changes in intestinal permeability.

In principle, the highly hydrophilic Gd-HPDO3A and Gd-DTPA complexes have an analogous behavior of the radioactive ${ }^{51}$ Cr-EDTA (36) and ${ }^{99 m}$ Tc-DTPA $(37,38)$ complexes, but their use could be considered preferable in terms of the higher safety. On the contrary, MultiHance ${ }^{\circledR}$ did not result to be a good intestinal permeability probe as its partial hepato-biliary elimination reduces its urinary recovery. 
The main advantage of the herein proposed method relies on the fact that the quantitative detection of Gd-based probes in urine is straightforward because their paramagnetism causes a marked decrease of the water proton relaxation time $\left(\mathrm{T}_{1}\right)$. This effect is largely exploited in the clinical use of these Gd-containing agents as they yield a dramatic increase in the MR signal of the tissues where they distribute. The measurement of the longitudinal relaxation time of water protons is routinely accessible on any NMR spectrometer. Actually, when one is only interested to acquire the strong ${ }^{1} \mathrm{H}$-water signal, it is customarily to use simplified versions of the NMR spectrometers called relaxometers. Several types of relaxometers are commercially available at highly affordable costs. The measurement of the longitudinal relaxation rate $\left(\mathrm{R}_{1 \mathrm{obs}}=1 / \mathrm{T}_{1 \mathrm{obs}}\right)$ of urine samples is then very easy and fast to acquire (1-5 min per sample) without any sample preparation or calibration.

Moreover, this method should be advantageous in respect to the classical $\mathrm{L} / \mathrm{M}$ test because the Gd-complexes to be used are larger (500-1000 Da), and thus they appear more suitable to discriminate between damaged and healthy intestinal membrane, and are not degraded by the colon bacteria, so they can be used to report on membrane damages along all the intestinal tract.

Although they are commonly administered intravenously, CAs formulations are available for oral administration for MRI investigation of the GI tract (e.g. Magnevist ${ }^{\circledR}$ Enteral, Bayer Schering Pharma AG). While one recognizes that the MRI CAs are more expensive and potentially subjected to higher toxicity than conventional sugars, the availability of clinically approved oral formulations of Gd-containing MRI agents may strongly accelerate the translation of the herein reported method from preclinical studies to applications on humans. For the detection step, one may envisage the use of compact 
and cheap relaxometers that can eventually be made available on the desk of doctor's offices or in pharmacy shops.

\section{Acknowledgements}

The Italian Minister of Research (MIUR) (Grant PRIN 2012SK7ASN and 20129JLHSY), AIRC Investigator Grant IG-14565, the Italian Consortium CIRCMSB and Compagnia di San Paolo are gratefully acknowledged. We thank Prof. Claudio Medana for the support in HPLC/MS analysis.

\section{References}

1) Miki K, Moore DJ, Butler RN, Southcott E, Couper RT, Davidson GP. The sugar permeability test reflects disease activity in children and adolescents with inflammatory bowel disease. J pediatr. 1998; 133:750-754.

2) Del Valle-Pinero AY, Van Deventer HE, Fourie NH, Martino AC, Patel NS, Remaley AT, Henderson WA. Gastrointestinal permeability in patients with irritable bowel syndrome assessed using a four probe permeability solution. Clinica Chimica Acta. 2013; 418:97-101.

3) Camilleri M, Madsen K, Spiller R, Van Meerveld BG, Verne GN. Intestinal barrier function in health and gastrointestinal disease. Neurogastroenterol Motil. 2012; 24:503-512.

4) Heyman M, Abed J, Lebreton C, Cerf-Bensussan N. Intestinal permeability in coeliac disease: insight into mechanisms and relevance to pathogenesis. Gut. 2012; 61:1355-1364. 
5) Teahon K, Smethurst P, Levi AJ, Menzies IS, Bjarnason I. Intestinal permeability in patients with Crohns-disease and their first degree relatives. Gut. 1992; 33:320-323.

6) McLaren W, Anikijenko P, Berkla D, Delaney TP, King R. In vivo detection of experimental ulcerative colitis in rats using fiberoptic confocal imaging (FOCI). Dig. Dis. Sci. 2001; 46:2263-2276.

7) Kim P, Chung E, Yamashita H, Hung KE, Mizoguchi A, Kucherlapati R, Fukumura D, Jain RK, Yun SH. In vivo wide-area cellular imaging by side-view endomicroscopy. Nat. Methods 2010; 7:303-305.

8) Aychek T, Vandoorne K, Brenner O, Jung S, Neeman M. Quantitative analysis of intravenously administered contrast media reveals cnahges in vascular barrier function in a murine colitis model. Magn. Reson. Med. 2011; 66:235-243.

9) Mishra A, Makharia GK. Techniques of functional and motility test: how to perform and interpret intestinal permeability. J Neurogastroenterol Motil. 2012; $18: 443-447$.

10) Camilleri M, Madsen K, Spiller R, Van Meerveld BG, Verne GN. Intestinal barrier function in health and gastrointestinal disease. Neurogastroenterol. Motil. 2012; 24:503-512.

11) Meddings JB, Gibbons I. Discrimination of site specific alterations in gastrointestinal permeability in rat. Gastroenterology. 1998; 114: 83-92.

12) Van Wijck K, Verlinden TJM, van Eijk HMH, Dekker J, Buurman WA, Dejong CHC, Lenaerts K. Novel multi-sugar assay for site specific gastrointestinal permeability analysis: a randomized controlled crossover trial. Clinical Nutrition. 2013; 32:245-251. 
13) Fleming SC, Kapembwa MS, Laker MF, Levin GE, Griffin GE. Rapid and simultaneous determination of lactulose and mannitol in urine by HPLC with Pulsed Amperometric Detection for use in studies of intestinal permeability. Clin. Chem. 1990; 36:797-799.

14) Bjarnason I, Peters TJ, Veall N. A persistent defect in intestinal permeability in coeliac disease demonstrated by a 51Cr-labelled EDTA absorption test. Lancet. 1983; 1:323-325.

15) Turck D, Ythier H, Maquet E, Deveaux M, Marchandise X, Farriaux JP, Fontaine G. Intestinal permeability to [51Cr]EDTA in children with Crohn's disease and celiac disease. J Pediatr Gastroenterol Nutr. 1987; 6:535-537.

16) Fotherby KJ, Wraight EP, Neale G. 51Cr-EDTA/14C-mannitol intestinal permeability test. Clinical use in screening for coeliac disease. Scand $J$ Gastroenterol. 1988; 23:171-177.

17) Stenhammar L, Falth-Magnusson K, Jansson G, Magnusson KE, Sundqvist T. Intestinal permeability to inert sugars and different-sized polyethyleneglycols in children with celiac disease. J Pediatr Gastroenterol Nutr. 1989; 9:281-289.

18) Troncone R, Starita A, Coletta S, Mayer M, Greco L. Antigliadin antibody, Dxylose, and cellobiose/mannitol permeability tests as indicators of mucosal damage in children with coeliac disease. Scand J Gastroenterol. 1992; 27:703706.

19) Andersen R, Stordahl A, Hoyseth H, Koppers R, Tverdal A, Aase S, Laerum F. Increased intestinal permeability for the isosmolar contrast medium iodixanol during small-bawel ischemia in rats. Scan. J. Gastroenterol. 1995; 30:10821088. 
20) Andersen R, Stordahl A, Aase S, Laerum F. Intestinal permeability of X-ray contrast media Iodixanol and Iohexol during bacterial overgrowth of small intestines in rats. Digest. Dis. Sci. 2001;46:208-213.

21) Aime S, Botta M, Terreno E. Gd(III)-based contrast agents for MRI. Advances in Inorganic Chemistry - including bioinorganic studies. Elsevier Academic Press Inc, San Diego, 2005; 57: 173-237.

22) Mustafi D, Fan X, Dougherty U, Bissonnette M, Karczmar GS, Oto A, Hart J, Markiewicz E, Zamora M. High-Resolution Magnetic Resonance Colonography and Dynamic Contrast Enhanced Magnetic Resonance Imaging in a murine model of Colitis. Magn. Reson. Med. 2010; 63:922-929.

23) Larsson AE, Melgar S, Rehnstrom E, Michaelsson E, Svensson L, Hockings P, Olsson LE. Magnetic Resonance Imaging of experimental mouse colitis and association with inflammatory activity. Inflamm. Bowel Dis. 2006; 12:478-485.

24) Young MR, Ileva LV, Bernardo M, Riffle LA, Jones YL, Kim YS, Colburn NH, Choyke P. Monitoring tumor progression in a mouse model of Inflammation induced Colon Cancer with Magnetic Resonance Colonography. Neoplasia 2009; 11:237-246.

25) Heilmann M, Walczak C, Vautier J, Dimicoli JL, Thomas CD, Lupu M, Mispelter J, Volk A. Simultaneous dynamic T1 and T2* measurement for AIF assessment combined with DCE MRI in a mouse tumor model. MAGMA 2007; 20:193-203.

26) Aime S, Geninatti Crich S, Gianolio E, Giovenzana GB, Tei L, Terreno E. High sensitivity lanthanide(III) based probes for MR-medical imaging. Coord Chem Rev. 2006; 250: 1562-1579. 
27) Fredin MF, Vidal A, Utkovic H, Gotlind YY, Willen R, Jansson L, Hornquist EH, Melgar S. The application and relevance of ex vivo culture systems for assessment of IBD treatment in murine models of colitis. Pharmacol Res. 2008; 58:222-31.

28) Siegmund B, Fantuzzi G, Rieder F, Gamboni-Robertson F, Lehr HA, Hartmann G, Dinarello CA, Endres S, Eigler A. Neutralization of interleukin-18 reduces severity in murine colitis and intestinal IFN-gamma and TNF-alpha production. Am J Physiol Regul Integr Comp Physiol. 2001; 281:1264-73.

29) Renes IB, Verburg M, Van Nispen DJPM, Taminiau JAJM, Büller HA, Dekker J, Einerhand AWC. Epithelial proliferation, cell death, and gene expression in experimental colitis: alterations in carbonic anhydrase I, mucin MUC2, and trefoil factor 3 expression. Int J Colorectal Dis. 2002; 17:317-326.

30) Qiu W, Wu B, Wang X, Buchanan ME, Regueiro MD, Hartman DJ, Schoen RE, Yu J, Zhang L. PUMA-mediated intestinal epithelial apoptosis contributes to ulcerative colitis in humans and mice. J Clin Invest. 2011; 121:1722-1732.

31) Camilleri M, Nadeau A, Lamsam J, Linker Nord S, Ryks M, Burton D, Sweetser S, Zinsmeister AR, Singh R. Understanding measurements of intestinal permeability in healthy humans with urine lactulose and mannitol excretion. Neurogastroenterol Motil. 2010; 22: e15-e26.

32) Terreno E, Geninatti Crich S, Belfiore S, Biancone L, Cabella C, Esposito G, Manazza AD, Aime S. Effect of the Intracellular Localization of a Gd-Based Imaging Probe on the Relaxation Enhancement of Water Protons. Magn Reson Med. 2006; 55:491-497. 
33) Vogl TJ, Pegios W, McMahon C, Balzer J, Waitzinger J, Pirovano G, Lissner J. Gadobenate dimeglumine-a new contrast agent for MR imaging: preliminary evaluation in healthy volunteers. Am J Roentgenol. 1992; 158:887-92.

34) de Haën C, Lorusso V, Luzzani F, Tirone P. Hepatic transport of the magnetic resonance imaging contrast agent gadobenate dimeglumine in the rat. Acad Radiol. 1995; 2:232-8.).

35) Pavone P, Patrizio G, Buoni C, Tettamanti E, Passariello R, Musu C, Tirone P, Felder E. Comparison of Gd-BOPTA with Gd-DTPA in MR imaging of rat liver. Radiology. 1990; 176:61-64.

36) Jenkins RT, Ramage JK, Jones DB, Collins SM, Goodacre RL, Hunt RH. Small bowel and colonic permeability to 51Cr-EDTA in patients with active inflammatory bowel disease. Clin Invest Med. 1988; 11:151-155.

37) Resnick RH, Royal H, Marshall W, Barron R, Werth T. Intestinal permeability in gastrointestinal disorders. Use of oral [99mTc]DTPA. Dig Dis Sci. 1990; 35:20511.

38) Sun SL, Wu SD, Zhang XB. Oral (99m)Tc-DTPA simultaneous determination of duodenobiliary reflux and intestinal permeability in patients after choledocholithotomy plus T-tube drainage. Hepatobiliary Pancreat Dis Int. 2005; 4:593-6.

\section{Figure Legends}

Scheme 1: Schematic representation of the study design.

Figure 1: Structures of the Gd-based Contrast Agents used in this study. 
Figure 2: Hematoxylin and Eosin staining of distal colon section of control (A) and DSS-treated (B) mice at day 9 (magnification 20X). DSS-induced colitis is histologically characterized by focal crypt damage, epithelial ulceration, hyperplasia and infiltration of inflammatory cells.

Figure 3: Intestinal permeability in DSS-treated mice (severe stage of damage) compared with untreated mice measured by the classical sugars test (A: L/M ratio, indicative of the small bowel permeability; B: percentage excreted Sucralose, indicative of colon permeability) and by the administration of the MRI CA ProHance ${ }^{\circledR}$ (C: black bar 0-6h, grey bar 6-12h collections). D) Linear correlation between the amount of excreted Gd and Sucralose. A Person test $(r=0.9138)$ was carried out obtaining a twotailed $\mathrm{P}$ value $<0.0001$. The correlation is significant at $99 \%\left(\mathrm{R}^{2}=0.8351\right)$.

Figure 4: (A) Urinary excretion of three commercial MRI CAs (ProHance $^{\circledR}$, Magnevist ${ }^{\circledR}$ and MultiHance ${ }^{\circledR}$ ) in DSS-treated mice (in the severe, day 3-4, and repairing, day 8-9 , stages of the damage) compared with control mice.

(B) Colon length and clinical score (C) of control and DSS-treated mice, administered with ProHance ${ }^{\circledR}$ (DSS P), Magnevist ${ }^{\circledR}$ (DSS MA) and MultiHance ${ }^{\circledR}$ (DSS MU), at day 9 $(\mathrm{n}=10, * * * \mathrm{P} \leq 0.001)$.

Figure 5: Observed longitudinal relaxation rates of urines of DSS-treated mice (in the severe, day 3-4, and repairing, day 8-9, stages of the damage) compared with those of control mice after the oral administration of the three commercial MRI CAs ProHance ${ }^{\circledR}$, Magnevist ${ }^{\circledR}$ and MultiHance ${ }^{\circledR}$. The urines collection was divided in the two intervals 06h, to investigate the small bowel permeability, and 6-24h to investigate colon permeability. 
Table 1: Retention times and mass/charge values for the four sugars.

\begin{tabular}{|lcc|}
\hline Analyte & Retention time (min) & $\mathrm{m} / \mathrm{z}$ \\
\hline Sucralose & 3.6 & $403+405+407(\mathrm{MW}+\mathrm{Li})$ \\
\hline Mannitol & 6.5 & $189\left(\mathrm{MW}+\mathrm{Li}^{+}\right)$ \\
\hline Lactulose & 9 & $349\left(\mathrm{MW}+\mathrm{Li}^{+}\right)$ \\
\hline Raffinose & 16 & $511\left(\mathrm{MW}+\mathrm{Li}^{+}\right)$ \\
\hline
\end{tabular}

Table 2: Colon length and clinical score of DSS-treated and control mice. These parameters were evaluated as described in Material and Methods. ( $\mathrm{n}=10, * * * \mathrm{P} \leq 0.001)$.

\begin{tabular}{|c|c|c|}
\hline \multicolumn{1}{|c|}{ Treatment } & Colon length & Clinical score \\
\hline water & $11,58 \pm 0,10$ & 1 \\
\hline DSS & $8,65 \pm 0,41^{* * *}$ & $5,7 \pm 1,25^{* * *}$ \\
\hline
\end{tabular}


Scheme 1

First (pilot) study

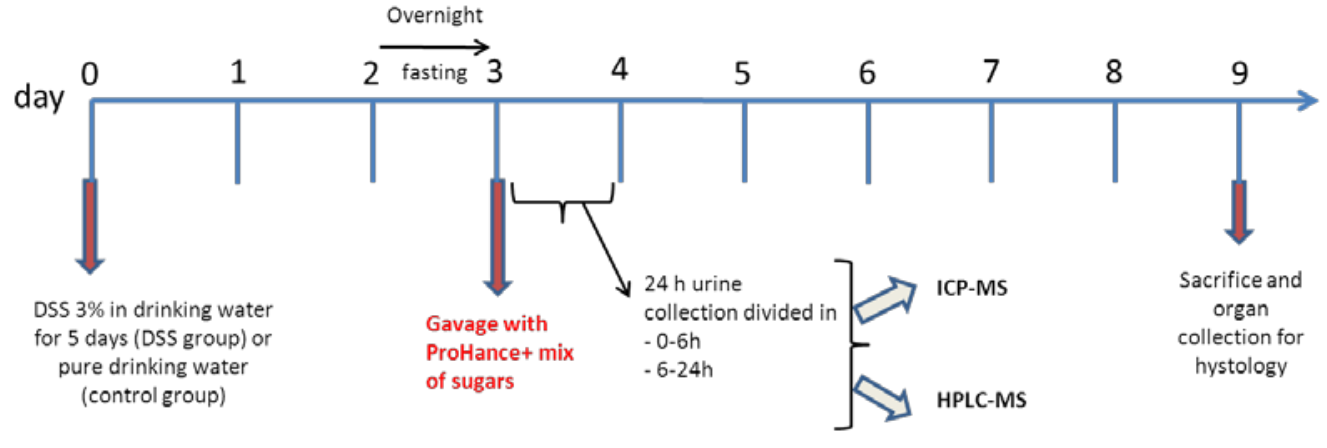

Second study

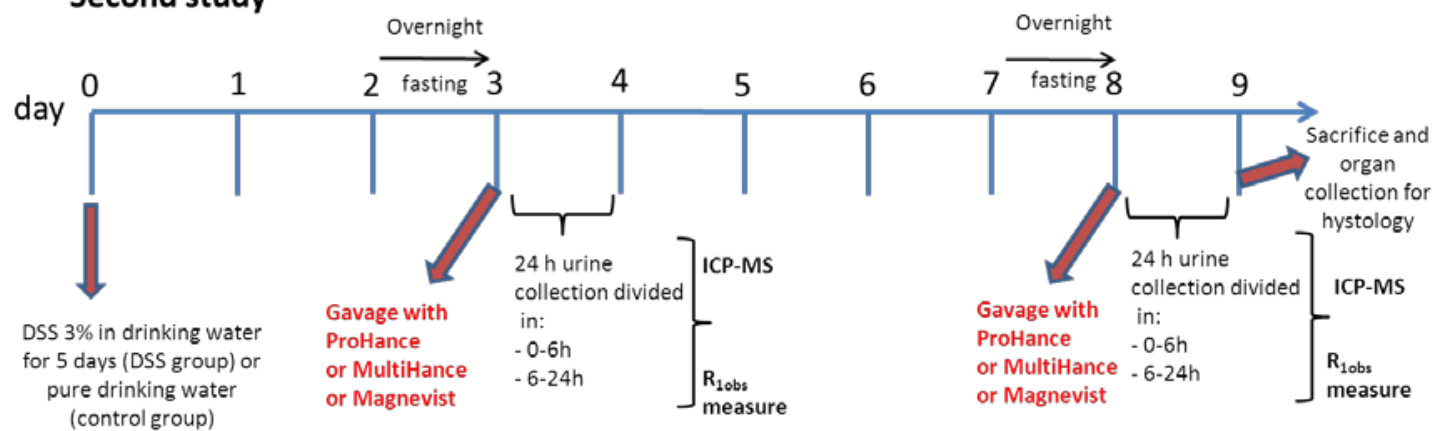




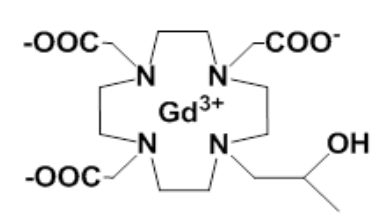

ProHance $\mathrm{MW}=558,7 \mathrm{Da}$

(Bracco Imaging)<smiles>O=C([O-])CN(CCN(CC(=O)[O-])C(=O)[O-])CCN(CC(=O)[O-])C(=O)[O-]</smiles>

Magnevist ${ }^{\circledR}$ $\mathrm{MW}=938,0 \mathrm{Da}$

(Bayer)<smiles>O=C([O-])CN(CCN(CC(=O)[O-])CC(=O)[O-])CCN(CC(=O)[O-])C(COCc1ccccc1)C(=O)[O-]</smiles>

MultiHance ${ }^{\circledR}$ $\mathrm{MW}=1058,2 \mathrm{Da}$

(Bracco Imaging)

Figure 1 


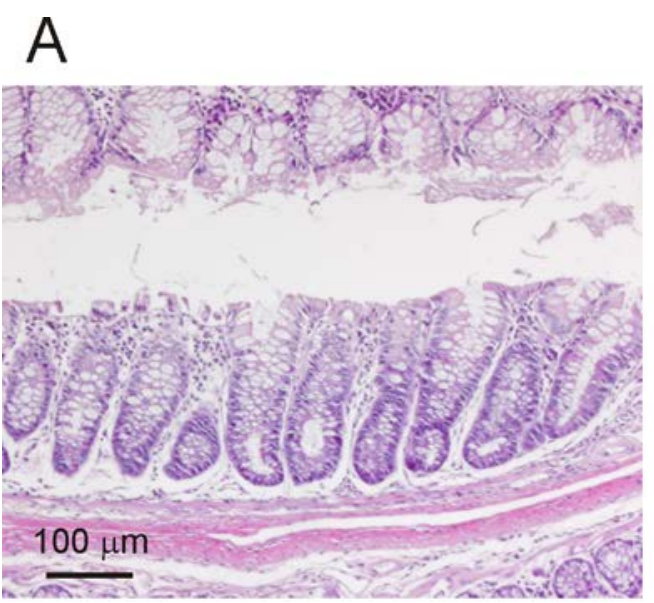

\section{B}

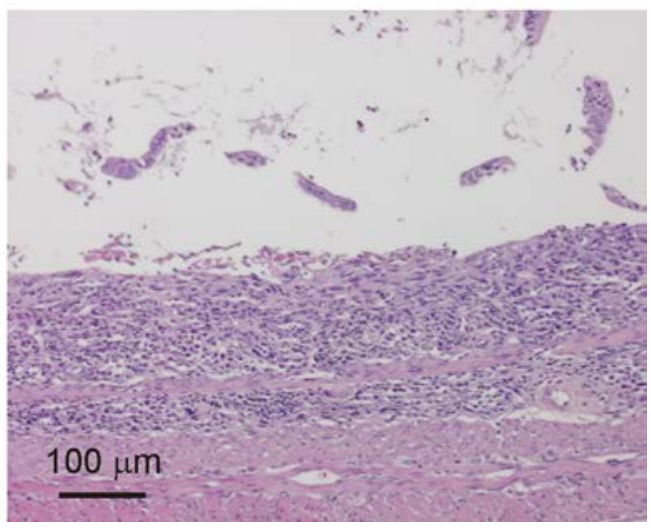

Figure 2 

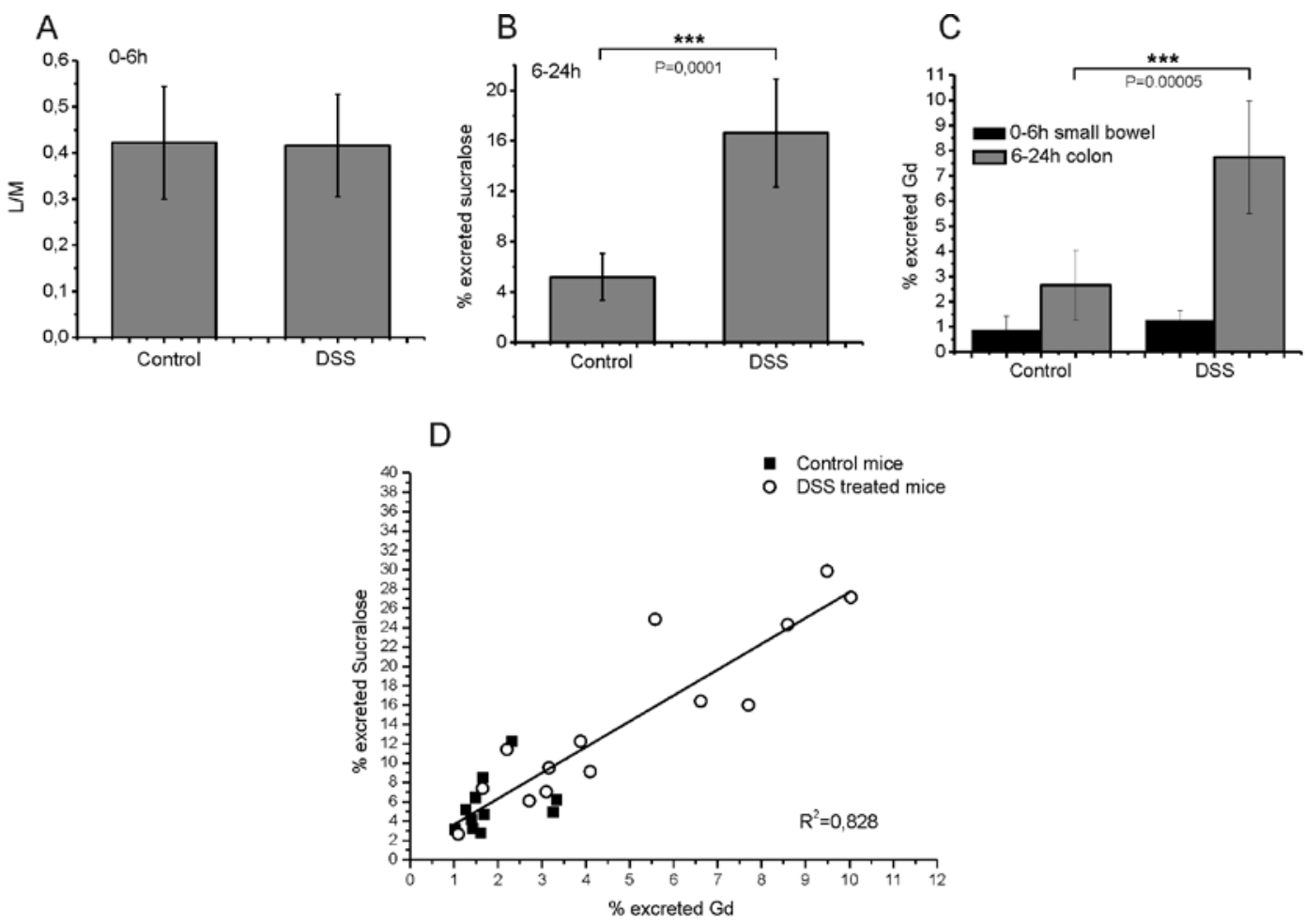

Figure 3 

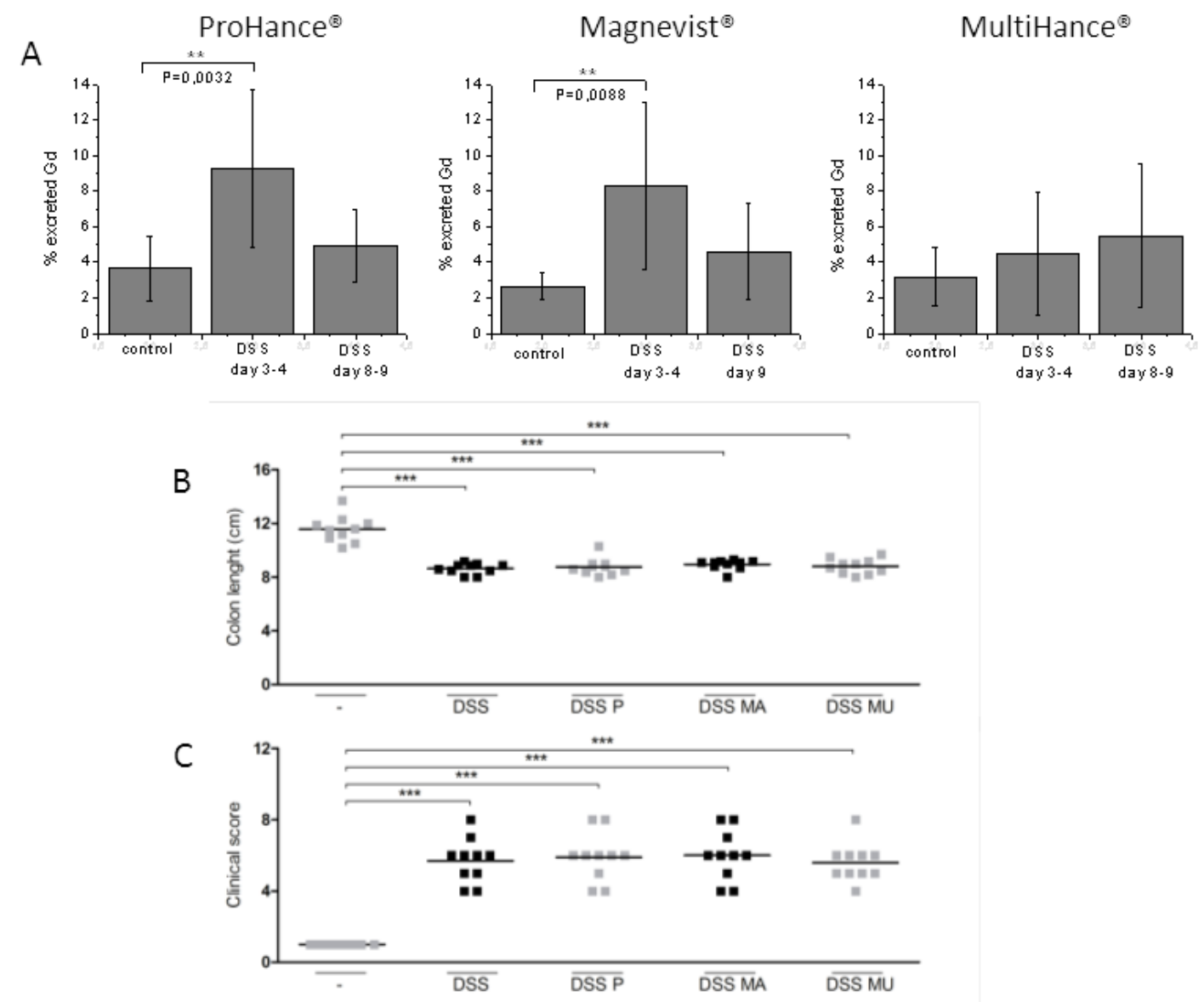

Figure 4 

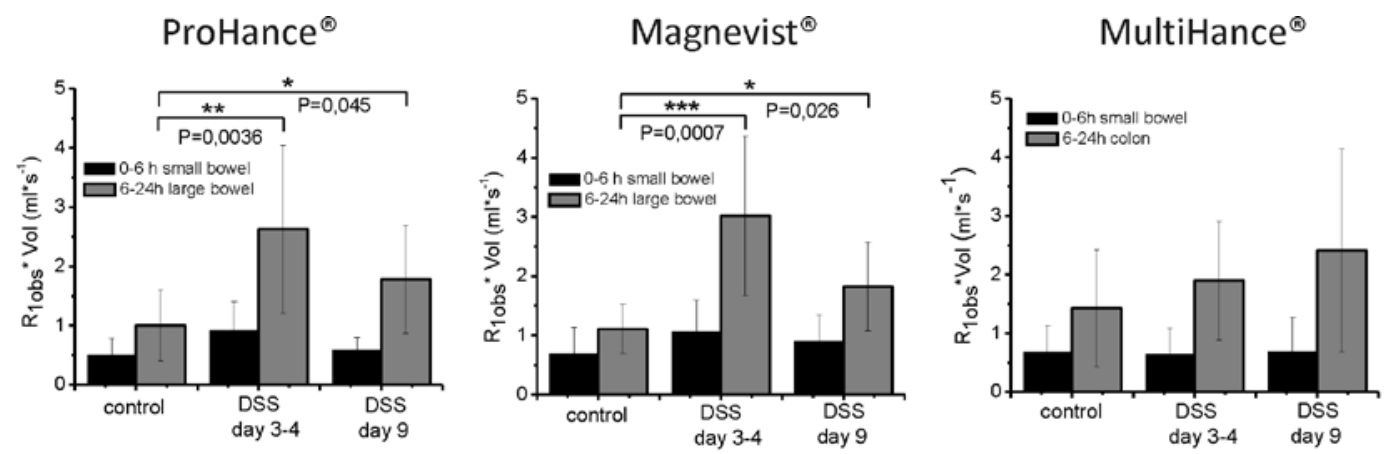

Figure 5 